\title{
Mesoscale eddies as foraging area of a deep-diving predator, the southern elephant seal
}

\author{
Frédéric Bailleul*, Cédric Cotté, Christophe Guinet \\ Centre d'Etudes Biologiques de Chizé, Centre National de la Recherche Scientifique,79360 Villiers en Bois, France
}

\begin{abstract}
Physical processes, such as mesoscale eddies, play an important role in ocean mixing and concentrating biological productivity, which provides great feeding opportunities for many marine top predators. This study describes the presumed foraging behaviour of southern elephant seals Mirounga leonina within an intense eddy field along the Polar Front in relation to the physical features of the eddies targeted by foraging seals, especially in the vertical dimension. Combining satellite measurements and data from tags deployed on elephant seals, we showed that some seals (10 of 38) preferentially selected the edge of cyclonic structures, generally associated with a high eddy kinetic energy, during intensive foraging phases. Moreover, we observed that elephant seals dived deeper within cyclonic eddies compared with anti-cyclonic structures. The behaviour of seals well illustrates the function of the spin-up of cyclonic eddies, where the upwelling of nutrients occurs at the centre, and high productivity and high concentration of prey occur at the edge. Productivity, aggregation of resources and accessibility of prey associated with cyclonic eddies probably act together to determine the selection of these structures by foraging elephant seals. However, eddies are not the only favourable foraging habitat within the Polar Frontal Zone, and the identification of oceanographic conditions associated with these other foraging zones requires further work.
\end{abstract}

KEY WORDS: Foraging behaviour · Bio-logging $\cdot$ Marine eddies $\cdot$ Vertical dimension $\cdot$ Mirounga leonina $\cdot$ Spatio-temporal distribution

Resale or republication not permitted without written consent of the publisher

\section{INTRODUCTION}

The pelagic environment is a highly heterogeneous and dynamic 3-dimensional habitat. Physical processes in the pelagic domain exert major control on biological activity and lead to substantial geographic variability in resources distribution. Among these processes, mesoscale eddies largely contribute to ocean mixing (e.g. Lévy 2008). Their role as 'oases' of biological productivity in the open ocean (Davis et al. 2002, Strass et al. 2002, Ream et al. 2005) is expected to have a crucial effect on the foraging strategy of marine predators. Recent work suggests the importance of eddies in providing foraging opportunities for sea birds (Nel et al. 2001, Weimerskirch et al. 2004, Cotté et al. 2007) as well as for other predators such as sea turtles (Ferraroli et al. 2004, Polovina et al. 2006), cetaceans (Davis et al. 2002) and southern elephant seals
Mirounga leonina (Campagna et al. 2006). However, few studies have investigated in detail how diving species use this dynamic environment to forage, especially if the vertical dimension is included, i.e. by relating the diving activity to the hydrological features of such structures at depth.

In the past 2 decades, bio-logging technology (Hooker et al. 2007), via electronic tagging and telemetry, has enabled collection of high resolution data of movement and diving behaviour of marine top predators and ambient water physical variables. In this manner marine predators can be used to monitor and measure hydrologic changes in their oceanic environment. Moreover, their foraging behaviour reflects the patchiness of oceanic biological production, a pattern generally associated with different physical structures (Charrassin \& Bost 2001, Pinaud \& Weimerskirch 2005). Hence, combining information on marine ecol- 
ogy and oceanography substantially increases our knowledge of biophysical interactions and our understanding of marine ecological patterns and processes.

Southern elephant seals are one of the major diving predators of the Southern Ocean in terms of population size and prey consumption (Hindell et al. 2003). These seals are known to make continuous deep dives all along their foraging trips (Hindell et al. 1991), sometimes reaching $2000 \mathrm{~m}$ in depth (Campagna et al. 1995). On average, dives last for 20 to $30 \mathrm{~min}$, allowing seals to make 50 to 70 dives per day (McConnell et al. 1992). Their mean swimming speed is about $7.2 \mathrm{~km} \mathrm{~h}^{-1}$ $\left(2 \mathrm{~m} \mathrm{~s}^{-1}\right)$ (Hindell \& Lea 1998). At sea (about 8 to $10 \mathrm{mo}$ $\mathrm{yr}^{-1}$ ), elephant seals make long migrations presumably searching for prey. During these migrations, they clearly modify their diving behaviour according to the areas visited (Bailleul et al. 2007a, 2008). For instance, during winter following the moulting season, 3 major foraging habitats were identified for the Kerguelen elephant seal population (Bailleul et al. 2010). One of these habitats is located between the Subtropical Front and the Polar Front and is referred to as the Polar Frontal Zone. In this area, the Antarctic Circumpolar Current (ACC) is characterised by intense mesoscale activity (Park et al. 2002, Kostianoy et al. 2004). The Polar Frontal Zone is an important foraging area for female seals regardless of their age, but is also used by juvenile males before they move to new foraging habitat, when they leave pelagic waters to feed in shelf waters (Bailleul et al. 2010).

The paired characteristics of wide-ranging movements and frequent deep dives make elephant seals ideal vectors for the deployment of oceanographic sensors, to characterise their foraging environment and gather physical oceanographic measurements (see Charrassin et al. 2008). Thus, elephant seals offer an ideal opportunity to explore in detail how marine predators exploit mesoscale eddies in both horizontal and vertical dimensions while foraging.

In general, 2 kinds of eddies can be distinguished in the southern hemisphere: the cyclonic, and the anticyclonic (clockwise and counter-clockwise rotating) eddies. When the eddy spins up the clockwise rotation leads to upwelling in the centre and downwelling on the edges; when it slows the forces reverse with downwelling occurring in the center and upwelling on the edge (Bakun 2006). Moreover, eddies have different dynamical properties between the inner and outer part of their structure. While the interior part of the eddy, or core, transports particles within it, the outer part produces intense stirring of the ambient environment (Olson 1991). These physical processes lead to both an enhanced productivity due to the upwelling of deep, nutrient rich waters and/or the spatial structuring and entrapment of the biological particles. These differ- ences should lead to some variation in the diving behaviour of elephant seals, which are expected to focus their feeding activity on the most productive zone.

In this study, we combined satellite measurements and data obtained from tags on elephant seals to collect information on the location of the seals, how deep they dived, and the characteristics of oceanic structures associated with presumed feeding dives. (1) Our aim was to investigate whether the most favourable (i.e. intensive) foraging zones within the Polar Frontal Zone were associated with eddies and which category of eddies, cyclonic or anti-cyclonic, was mainly targeted by seals. (2) We wanted to assess whether elephant seals forage preferentially at the edge or in the core of the eddies. (3) We tried to physically characterise in 3 dimensions (3D) those eddies that corresponded to the most favourable foraging areas.

\section{MATERIALS AND METHODS}

Seal capture and deployment of devices. From 2003 to 2007, 46 southern elephant seals ( 24 females and 22 males) were captured at Kerguelen Islands $\left(49^{\circ} 20^{\prime} \mathrm{S}\right.$, $70^{\circ} 20^{\prime} \mathrm{E}$ ) by means of a canvas head-bag. A 1:1 combination of tiletamine and zolazepam (Zoletil 100) anaesthetic was injected intravenously to immobilize the seals before attaching data loggers (McMahon et al. 2000, Field et al. 2002). During the study, 3 satelliterelayed data loggers were deployed to measure temperature and depth (TD-SRDL) and 43 were deployed to measure conductivity, temperature and depth (CTDSRDL). Data loggers were used on both sexes. The data loggers $(105 \times 70 \times 40 \mathrm{~mm}, 545 \mathrm{~g}$, cross-sectional area $28 \mathrm{~cm}^{2}$ ) were designed and manufactured by the Sea Mammal Research Unit (SMRU), University of St Andrews, UK, to collect and transmit locations, pressure (depth), ambient temperature and conductivity. In this study we only used temperature to characterise the ambient environment. Temperature was measured to an accuracy of $\pm 0.005^{\circ} \mathrm{C}$. The instruments were pressure-rated to $2000 \mathrm{~m}$. Data were sampled every $2 \mathrm{~s}$ but the Argos data system did not enable all records to be transmitted. A pseudo-random method to schedule the transmission of an unbiased data sample of the stored records was used (Fedak 2004). This new generation of logger transmits the collected information by satellite in near real-time, which allowed us to relate the seal's pelagic behaviour with the immediate oceanic environment. Eighteen juvenile males (i.e. about 2 to $4 \mathrm{yr}$ in age according to their size and not having reached sexual maturity) and all adult female elephant seals were equipped with data loggers between November and March, before their departure 
for their post-moult foraging trip. Four juvenile males were also equipped with data loggers in September during a short winter visit on land. The recorders were glued onto the head of the seals with quick-setting epoxy (Araldite AW 2101) after the hair had been cleaned with acetone. This study was approved by the ethics committee of the French Polar Institute (IPEV) and all seals were cared for in accordance with its guidelines.

Seal locations. Locations were determined during satellite uplinks by the Argos system. However, the raw track presented numerous outliers and post-processing of locations was necessary. A location class (LC) was provided for each location by the Argos system. LC was '0','1',' 2 ' or '3' when more than 3 uplinks were available, whereas the LC 'A' was assigned when only 3 uplinks were available and the LC 'B' was assigned when only 2 uplinks were available. The lower the number of uplinks, the more uncertain was the location accuracy. The accuracy of locations was as follows: LC ' 3 ' was accurate to $150 \mathrm{~m}, \mathrm{LC}$ '2' to $350 \mathrm{~m}$, $\mathrm{LC}$ ' 1 ' to $1 \mathrm{~km}, \mathrm{LC}$ ' 0 ' over to $1 \mathrm{~km}$, and LC 'A' and 'B' had no accuracy assigned. The seals' underwater habits resulted in a high proportion of locations of nonguaranteed accuracy (Classes A and B). Approximately $40 \%$ of elephant seal data are in Class B and approximately $24 \%$ are in Class A, so it is impossible to reject locations on the basis of an LC criterion. Two possible locations are provided by the Argos system for each point. The algorithm, which chooses the true location between them, can sometimes fail; thus, the first correction step was to replace outliers by their homologous points. Then, unrealistic satellite locations were rejected by means of a forward/backward averaging filter (McConnell et al. 1992), based on the assumption that seals rarely travel at speeds $>3 \mathrm{~m} \mathrm{~s}^{-1}$. Finally, a 24 h running mean was applied to locations, and the locations were resampled at regular $3 \mathrm{~h}$ intervals for practical analysis. The 46 individual paths were described by $2431 \pm 1988$ (mean \pm SD) locations, corresponding to $22 \pm 9$ locations $\mathrm{d}^{-1}$. The locations of individual dives along these paths were estimated based on a simple linear interpolation of the distance between locations. The study area included all tracks from 50 to $140^{\circ} \mathrm{E}$ and 35 to $70^{\circ} \mathrm{S}$.

Diving behaviour and intensive foraging areas. Dive duration and maximum depth were the main diving variables recorded. On any dive, a seal was assumed to be at the bottom of the dive whenever depth exceeded $80 \%$ of the maximum depth (Lesage et al. 1999, Schreer et al. 2001). Dive types with a long bottom time were presumed to represent foraging activity because the seals were expected to maximise the proportion of time spent at a particular depth where prey might be encountered (Schreer et al. 2001). To identify the loca- tion of foraging areas, we applied first passage time (FPT) analysis to the variability of time spent at the bottom of a dive (see Bailleul et al. 2008). Thus, we calculated the residuals of the multiple regression (bottom time versus maximum dive depth plus dive duration) for each dive within a path. Then we calculated the sum of the absolute values of these residuals within a circle of given radius (see FPT method in Fauchald \& Tveraa 2003). This value represented the variation of the relative bottom time of dives between the first passage of the circle, backward and forward along the path at surface. This value will increase as the radius $(r)$ of the circle increases. However, the increase will be especially large when individuals significantly change their behaviour (e.g. when they adopt an area-restricted search behaviour). Thus, the relative variance for all points along the path will increase with increasing $r$ (see Fauchald \& Tveraa 2003). If search behaviour is concentrated within a certain area, we expect a maximum variance, with $r$ corresponding to the spatial scale of the most intensive area searched. Once the spatial scale was identified, we calculated the sum of residuals within each circle. Thus, we obtained a measure of change in behaviour at depth, called residual first bottom time (rFBT) (Bailleul et al. 2008). The rFBT corresponding to the scale of the maximum variance was plotted against time from departure for each individual, and we identified zones where the seals spent a longer (positive sum of residuals) time than expected at the bottom of dives (Bailleul et al. 2008). Then, from 'drift dives' identified by classification (see Bailleul et al. 2007a), drift rate was assessed according to the time and 'combined' with the rFBT analysis. Thus, an increasing trend in drift rate, which is indicative of presumed body condition improvement (Biuw et al. 2003, 2007, Bailleul et al. 2007b), combined with the area determined by rFBT, corresponded to the best approximation of what we refer to as an 'intensive foraging phase' (Bailleul et al. 2007b, 2008). These areas were contrasted to the part of the trip remaining, hereafter referred to as 'non-foraging phase'.

Intense eddy field determination. In the present study, we have defined spatial limitations of the eddy field from the annual variance of sea level anomalies (SLA) within the study area during the time of tracking. The eddy field was identified by the variances of up to $20 \mathrm{~cm}$ to select the maximum range of eddy structures. The merged (i.e. stemming from several satellites) SLA data $\left(0.3^{\circ}\right.$ grid $)$ were mapped based on the archiving, validation and interpretation of satellite oceanographic data from the Collect Localization Satellite (CLS, Centre National d'Etudes Spatiales, France) project for the Segment Sol multi-missions dALTimetrie, d'Orbitographie et de localisation precise (SSALTO) program. Despite possibilities of error 
due to differences in ground tracks and orbit repeat periods among the several altimeter instruments and to interpolation in the grid construction, merged data have the advantage of resolving mesoscale oceanic processes beyond the capability of a single instrument (Fu et al. 2003).

Seal and current direction within the eddy field. Geostrophic currents $\left(0.3^{\circ}\right.$ resolution) were computed from SLA and meridian $(u)$ and zonal (v) geostrophic current components and were used to determine current direction as follows:

$$
u=-(g / f) \frac{\delta H}{\delta y} \text { and } v=(g / f) \frac{\delta H}{\delta x}
$$

where $g=980 \mathrm{~cm} \mathrm{~s}^{-2}, f=2 \Omega \sin \Phi$ with $\Omega=7.29$ radians $\mathrm{s}^{-1}, \Phi$ is the latitude and $H$ is sea level anomaly. Daily SLA were extracted from the seal locations and current components were calculated from these values of SLA for each seal location. Seal direction was defined by a straight line (i.e. a supposed straight movement between 2 successive positions). Thus, by means of circular statistics bearing deviations between elephant seals and underlying current directions, varying from 0 to $360^{\circ}$, were investigated. A bearing deviation from 270 to $0^{\circ}$ and $0^{\circ}$ to $90^{\circ}$ signified similar directions for seals and the current, while a bearing deviation from 90 to $270^{\circ}$ corresponded to opposing directions (Ream et al. 2005, Cotté et al. 2007). Similar (270 to $90^{\circ}$ ) directions suggested that currents assisted the directional movements of the seals, whereas opposing (90 to $270^{\circ}$ ) directions suggested opposing forces.

Detection, structure and sense of rotation of eddies. Analysis of numerical results on 2-dimensional turbulent flows have been proposed based on the general criterion of the Okubo-Weiss parameter $(W)$ (Okubo
1970, Weiss 1991) to detect and determine the detailed structure of an eddy (core versus edge). The OkuboWeiss parameter is defined as: $W=s_{\mathrm{n}}^{2}+s_{\mathrm{s}}^{2}-\omega^{2}$, where $s_{\mathrm{n}}$ and $s_{\mathrm{s}}$ are the normal and the shear components of strain, and $\omega$ is is the relative vorticity of the flow; all are defined by:

$$
s_{\mathrm{n}}=\frac{\partial u}{\partial x}-\frac{\partial v}{\partial y}, s_{\mathrm{s}}=\frac{\partial v}{\partial x}+\frac{\partial u}{\partial y}, \omega=\frac{\partial v}{\partial x}-\frac{\partial u}{\partial y}
$$

According to the operator sign, this parameter allows for flows to be separated into different regions: a vorticity-dominated region $\left(W<-W_{0}\right)$, a strain-dominated region $\left(W>W_{0}\right)$ and a background field, characterised by small positive and negative values of $W$ (i.e. $|W| \leq$ $-W_{0}$ ). The component $W_{0}=0.2 \sigma_{W}$, with $\sigma_{W}$ being the $\mathrm{SD}$ in the whole domain, in this instance the area from 60 to $148^{\circ} \mathrm{E}$ and from 35 to $70^{\circ} \mathrm{S}$.

When applying this criterion of flow partition, the general structure of an eddy consists of an inner region (core) which is surrounded by a circulation cell (eddy edge) (Elhmaïdi et al. 1993) (Fig. 1). Using the OkuboWeiss parameter extracted for each seal location, we assessed the position of seals as either inside or outside an eddy and clarified whether the seals were located within the eddy core or within the eddy edge. Using SLAs associated with the eddies, we also identified their direction of rotation. Negative values corresponded to cyclonic, positive values to anti-cyclonic eddies (Fig. 1).

Eddy kinetic energy computation. Once the eddy had been identified, we estimated the surrounding eddy kinetic energy (EKE). EKE is defined as the energy associated with the turbulent part of the flow of a fluid and is computed in our study from geostrophic currents and, therefore, from SLA (see 'Intense eddy

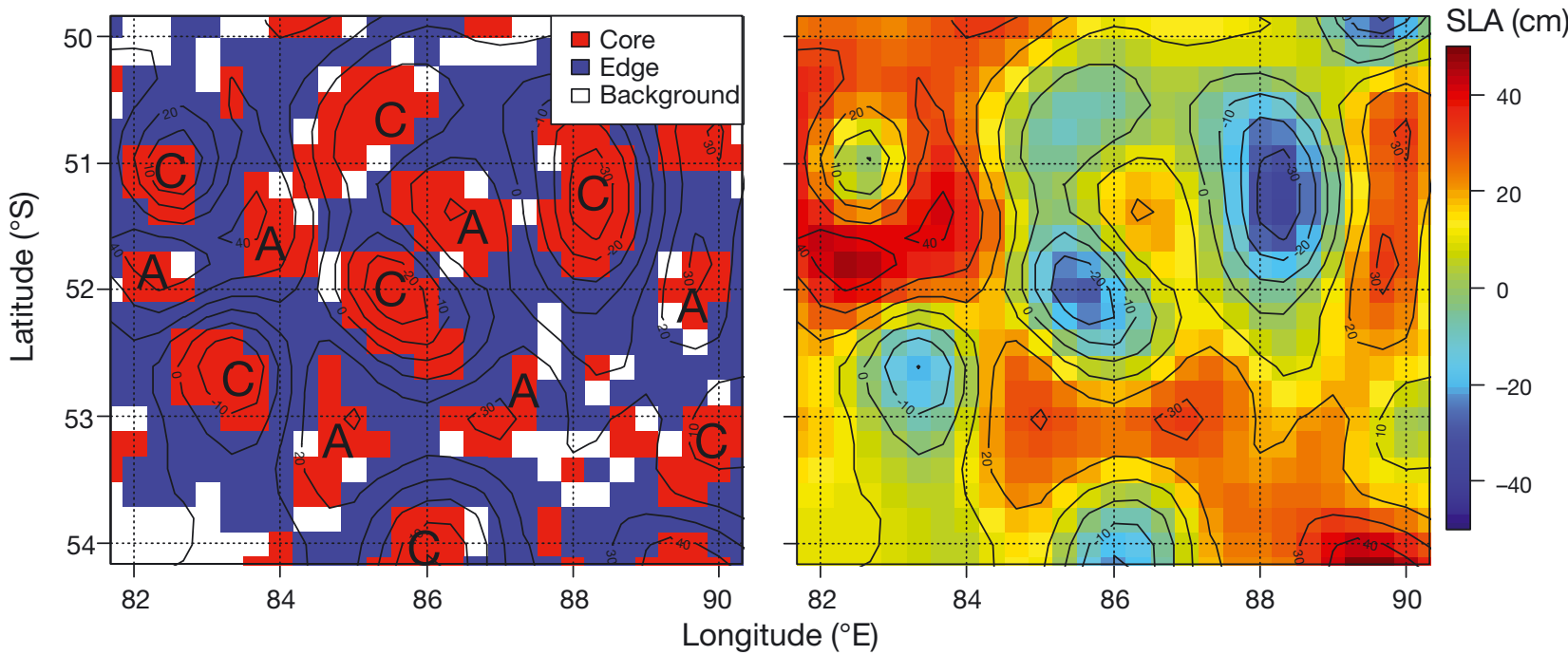

Fig. 1. Left panel: eddies identified by the Okubo-Weiss parameter. The direction of rotation of each structure is given by the corresponding sea level anomaly (SLA) values (right panel). C: cyclonic (clockwise); A: anti-cyclonic (counter-clockwise) 
field determination'). The formula used to calculate EKE was:

$$
\mathrm{EKE}=1 / 2 \times\left(u^{2}+v^{2}\right),
$$

where $u$ and $v$ are the meridian and zonal geostrophic currents components, respectively.

To determine the intensity of eddy flows crossed by seals, we considered an eddy mean radius of $90 \mathrm{~km}$ (Park et al. 2002, Swart et al. 2008) and we extracted the EKE maximal value included between 0 and $90 \mathrm{~km}$ around each seal location. From these values, we then compared the intensity of eddy flows crossed by the seals during 'non-foraging phases' to that during 'intensive foraging phases'.

Statistical analysis. We tested the behaviour of seals in relation to mesoscale structures by means of linear mixed effect subject model (LME) and generalised linear model (GLM) with Individual as a random effects subject term and Year as a fixed effect in the $\mathrm{R}$ package (R Development Core Team).

\section{RESULTS}

\section{Seal movements and mesoscale current}

Mesoscale currents due to eddies were variable in both time and amplitude (Fig. 2). We observed that currents encountered along the tracks of elephant seals did not influence their direction in neither the non-foraging phase nor the intensive foraging phase, as no deviation appeared from $270^{\circ}$ to $90^{\circ}$.

\section{Distribution in eddy field}

The recording duration was short $(<32$ d) for 8 seals and these were removed from the analysis. Therefore, the following results were computed for 18 post-moult adult females and 20 post-moult immature males. Of the 38 remaining seals, 16 (9 females and 7 males) spent $>60 \%$ of their recorded trip duration moving through the eddy field. However, when we compared the spatial distribution of the locations associated with an intensive foraging phase with those associated with an eddy structure, we found that only 10 individuals, mainly females (8 females versus 2 males), presented at least 1 clear intensive foraging phase within eddy structures. All these seals were foraging east of Kerguelen Island (Fig. 3). The following analyses were conducted for these 10 individuals.

\section{Intensive foraging phases and eddies}

The spatial scale and therefore the mean size of intensive foraging areas obtained by the rFBT method was a circle with a radius of $92 \pm 64 \mathrm{~km}$. The combination of these areas with the location of eddies, defined using the Okubo-Weiss parameter, revealed that individuals targeted mesoscale structures to a much greater extent during intensive foraging phases compared with non-foraging ones (GLM: $t=30.36$, p < $0.001)$. Indeed, 3490 of the 4228 presumed feeding locations $(\sim 82 \%)$ were located within eddies, while 736 $(18 \%)$ remained in the background field. In contrast, during the non-foraging phase, 11962 (43\%) seal positions were located in the background field, while 16016 (57\%) were located within mesoscale eddies.

The direction of rotation of eddies determined by SLA values was significantly different between the intensive foraging phase (cyclonic) and the non-foraging phase (anti-cyclonic) (LME: $t=-30.40, \mathrm{p}<0.001$ ). Moreover, the distribution of SLA associated with the non-foraging phase, which was skewed toward positive values, was not different from the distribution of SLA within the eddy field (chi-squared $=3.44, \mathrm{p}=0.94$ ) (Fig. 4a). However, the distribution of SLA extracted for the locations associated with the intensive foraging phase, which was skewed toward negative values, was significantly different from that within the eddy field (chi-squared $=42.54, \mathrm{p}<0.001$ ) (Fig. 4b). This suggests that seals preferentially selected cyclonic eddies during intensive foraging phases.

Following the Okubo-Weiss parameter, elephant seals associated with cyclonic eddies during intensive foraging phase were found to target mainly the edge of these structures (GLM: $t=-4.63, \mathrm{p}<0.001)$. Indeed, of 


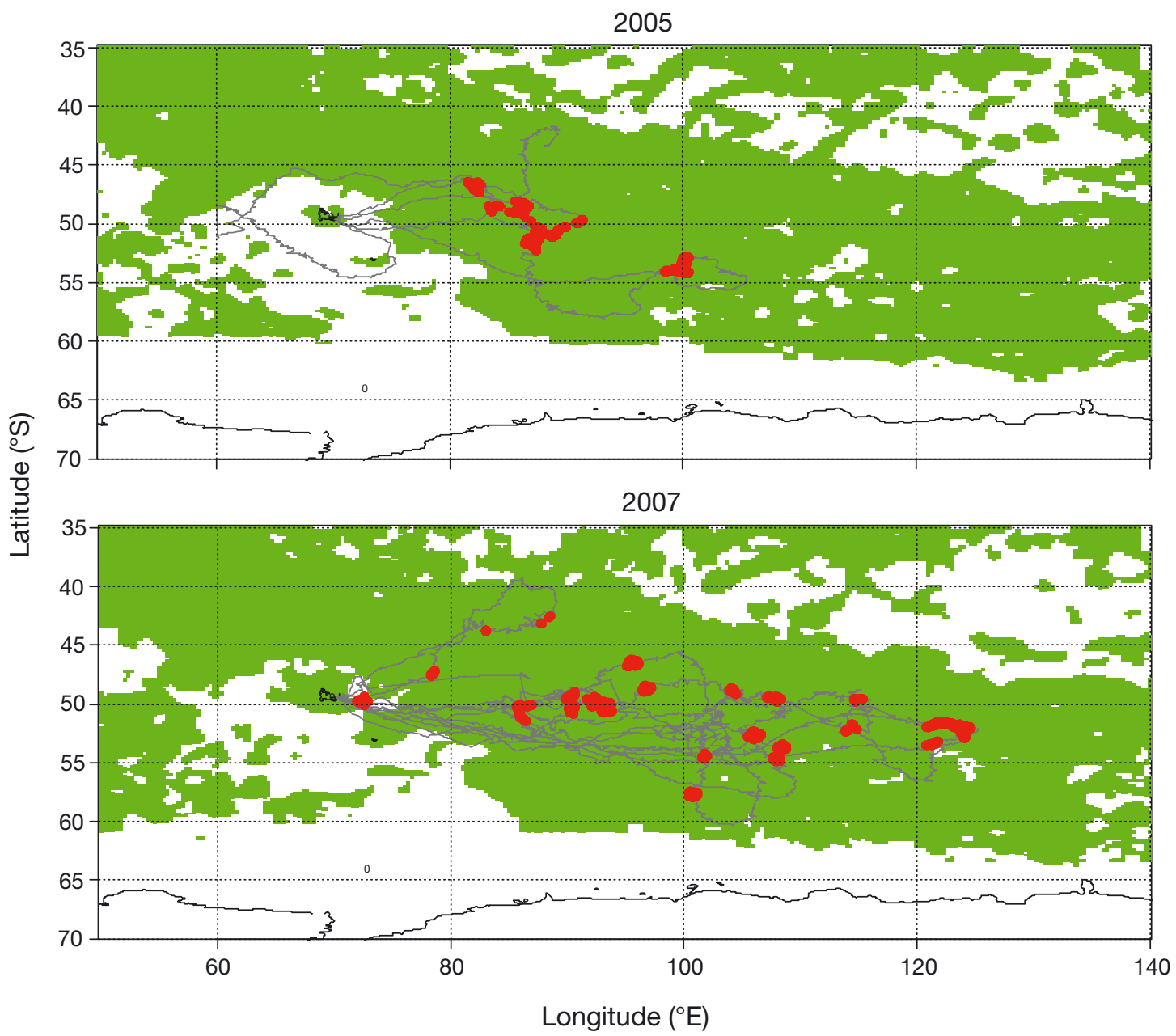

Fig. 3. Mirounga leonina. Elephant seal tracks (grey lines) used in the analyses. Green: eddy field as determined by the variance of sea level anomalies during the total time of tracking. Red: most intensive foraging areas, identified by the residual first bottom time

2310 locations associated with intense foraging phase within cyclonic eddies, $1502(\sim 65 \%)$ were located at the edge of mesoscale structures.

\section{Individual properties of favourable eddies}

The distribution of EKE values within the eddy field was skewed toward low values $\left(217 \pm 7 \mathrm{~cm}^{2} \mathrm{~s}^{-2}\right.$ on daily average), while EKE distributions extracted for seal positions both during non-foraging and intensive foraging phases were significantly different (chisquared $=139, \mathrm{p}<0.001$ and chi-squared $=181, \mathrm{p}<$ 0.001, respectively) (Fig. 5). Moreover, EKE values differed significantly between the intensive foraging and the non-foraging phases (LME: $t=-5.71, \mathrm{p}<$ 0.001). During non-foraging phases, seals crossed structures with a large range of EKE values (i.e. 850 to
$1550 \mathrm{~cm}^{2} \mathrm{~s}^{-2}$ corresponding to maximum density of the unimodal distribution) (Fig. 5a). EKE distribution associated with intensive foraging phase locations was bimodal and ranged between 550 to 1050 and 1450 to $1750 \mathrm{~cm}^{2} \mathrm{~s}^{-2}$ (Fig. 5b).

\section{Diving behaviour within favourable cyclonic eddies}

During intensive foraging phases, both the direction of the rotation of eddies (cyclonic versus anti-cyclonic) and the interaction between this parameter and SLA values affected the diving depth of elephant seals (LME: $t=-2.07, \mathrm{p}=0.04$ and $t=4.40, \mathrm{p}<0.001$, respectively). Within cyclonic eddies, it appeared that the higher the SLA values, the deeper the elephant seals dived, while no relationship was observed with anticyclonic structures (Fig. 6). 


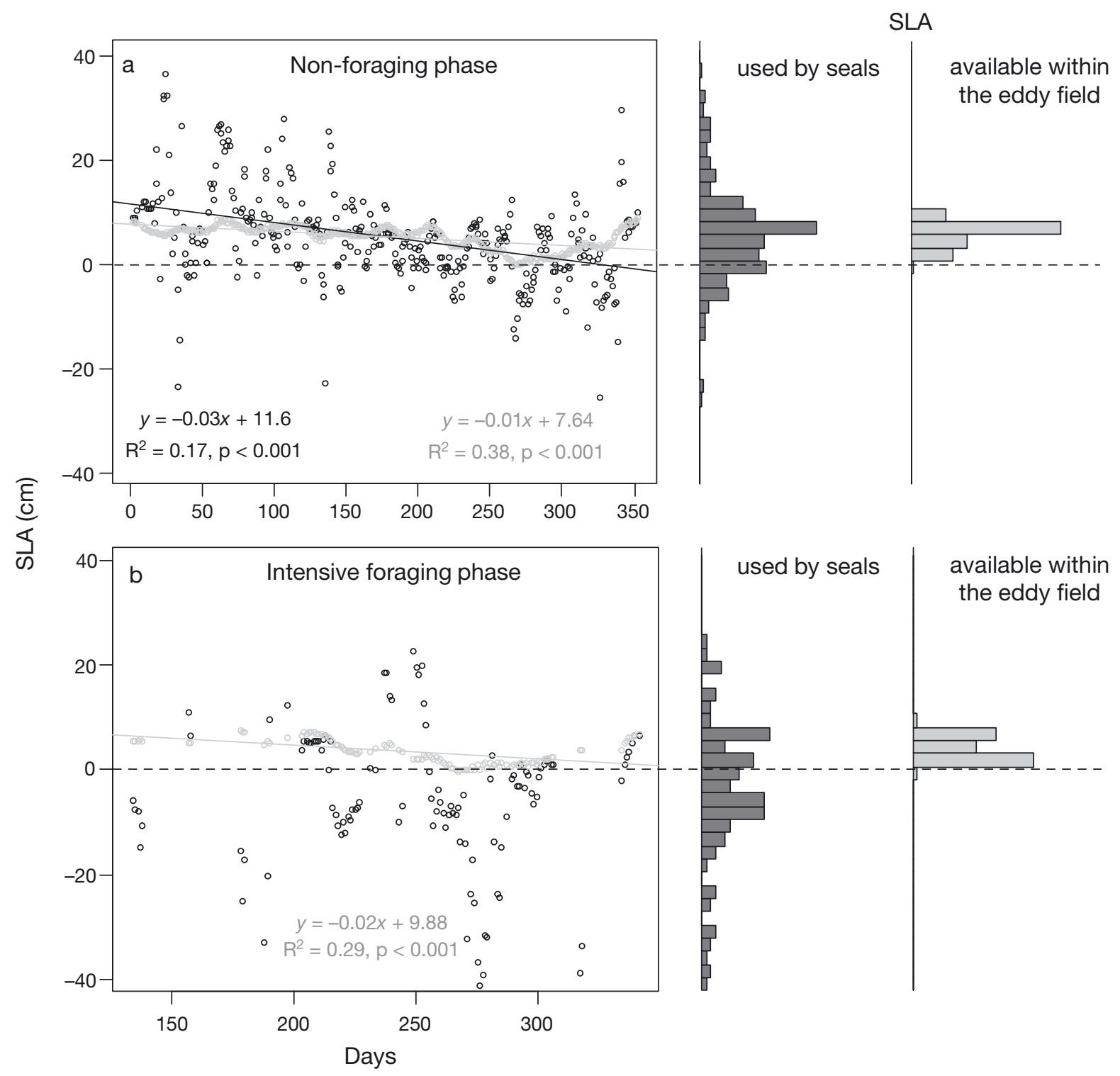

Fig. 4. Mirounga leonina. Daily average of sea level anomalies (SLA) values within the eddy field ( $($ ) and extracted for elephant seal positions ( $(0)$ during (a) the non-foraging phase and (b) the intensive foraging phase. Regression lines illustrate the difference between which values are used and which ones are available according to the time. This difference was not significant for the non-foraging phase, while it was for the intensive foraging ones. Right panels: distribution of SLA used by seals (dark grey) and SLA available in the eddy field (light grey) for the non-foraging and intensive foraging situation

\section{Vertical structure of favourable cyclonic eddies}

The vertical sections provide a depiction of the characteristics of cold eddies targeted by seals for foraging (Fig. 7). These sections were obtained from depth-temperature profiles recorded by different seals along their tracks. The outstanding feature of the temperature profiles was the core of cold water that stretched mainly between 200 and $400 \mathrm{~m}$ where temperatures fell below $2^{\circ} \mathrm{C}$. The cores of these cyclonic eddies were up to $2^{\circ} \mathrm{C}$ colder than the waters surrounding the eddy and were capped by a strong thermocline. A weak temperature gradient existed in depth between eddies and their surrounding well-mixed surface waters. The upper $400 \mathrm{~m}$ of the eddy was globally characteristic of Antarctic surface waters, with the cold core of eddies corresponding to the subsurface temperature minimum layer of 'winter water'. From 200 to $1000 \mathrm{~m}$, the $2.5^{\circ} \mathrm{C}$ isotherm marked the boundary of the eddy with the 


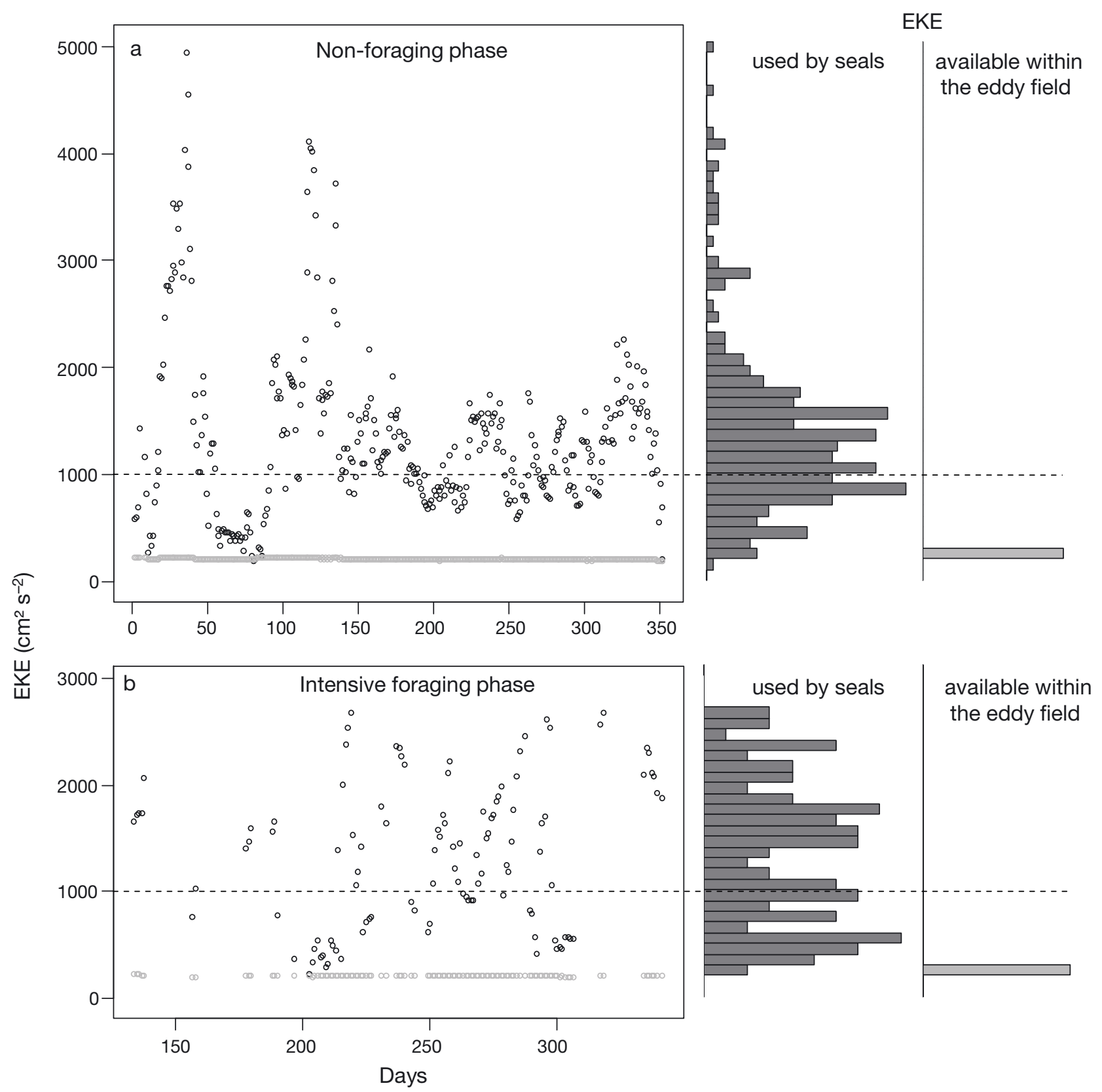

Fig. 5. Mirounga leonina. Daily average of eddy kinetic energy (EKE) values within the eddy field ( $($ ) and extracted in a circle with $90 \mathrm{~km}$ radius around each position (o) during (a) the non-foraging phase and (b) the intensive foraging phase. Right panels: distribution of EKE used by seals (in dark grey) and EKE available in the eddy field (light grey) for the non-foraging and intensive foraging situation

warmer surrounding environment. The vertical temperature sections at the edge of cyclonic eddies are shown in Fig. $7 \mathrm{a}, \mathrm{b}$, while the core of the structures where the $2.5^{\circ} \mathrm{C}$ isotherm appears deeper are shown in Fig. $7 d$,e. In Fig. $7 \mathrm{c}$, as the track at surface was observed along the edge, the pattern observed in depth could be explained by an incursion of this individual in the core of eddy while diving.

\section{DISCUSSION}

Mesoscale eddies in the Southern Ocean are known to have a significant effect on primary productivity (e.g. Pakhomov \& Fronemann 2000, Strass et al. 2002) and on the creation of preferred feeding regions for marine predators (e.g. Nel et al. 2001, Cotté et al. 2007). Despite the example of the diving pattern of a 

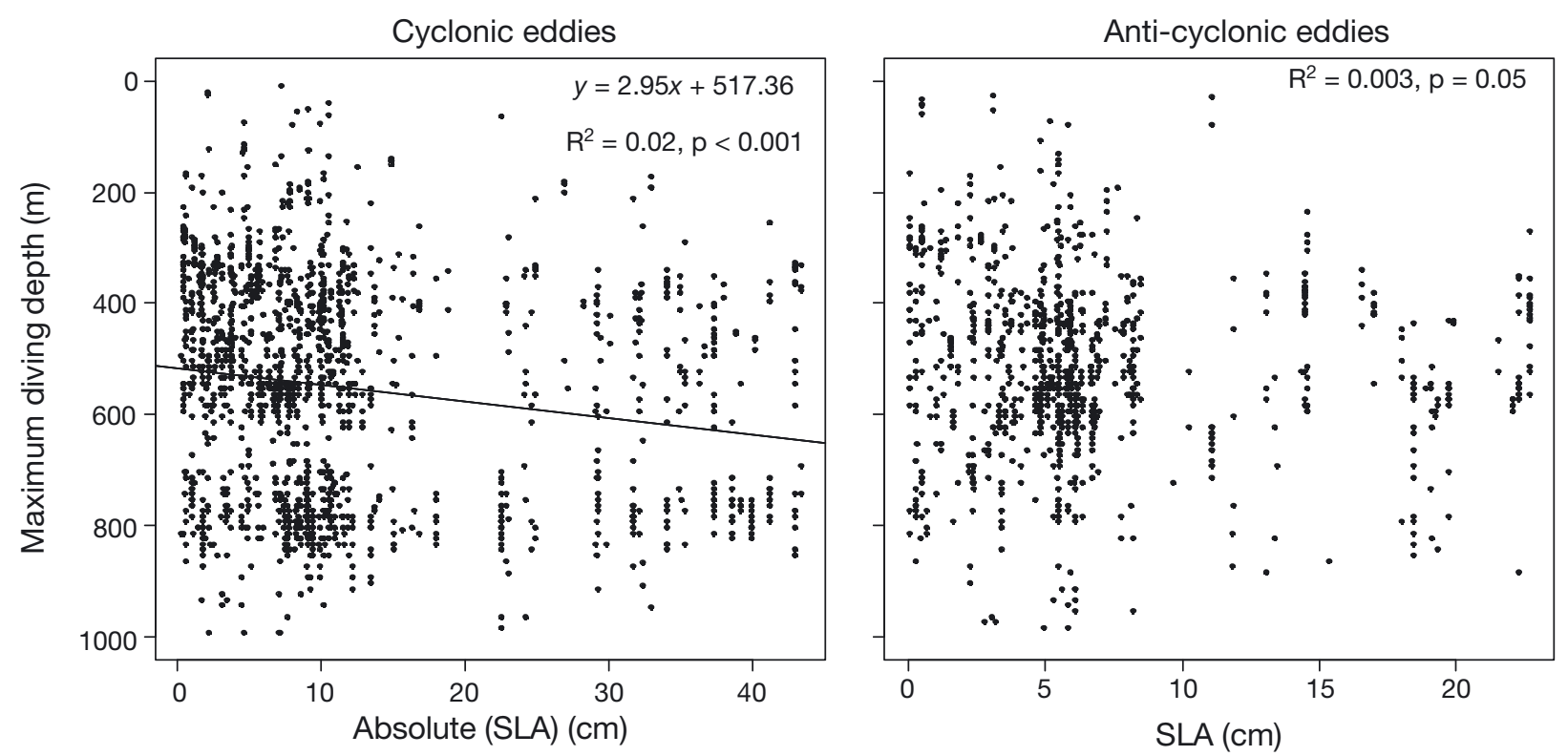

Fig. 6. Mirounga leonina. Relationship between the maximum diving depth of elephant seals and the sea level anomaly (SLA) values only during the intensive foraging phases for both cyclonic and anti-cyclonic eddies

single elephant seal inside an eddy relative to temperature in the study by Campagna et al. (2006), no study has investigated in detail by means of a 3-dimensional approach, the relationship between the foraging behaviour of a deep-diving marine mammal and physical features of such key oceanic structures. The present study showed that about $60 \%$ of Kerguelen elephant seals, travelling within the Polar Frontal Zone, focussed their intensive foraging activity within eddy structures. As an indication of such activity, the mean size of seal intensive foraging areas (about $90 \mathrm{~km}$ radius) was consistent with the mean size of eddies in this area (Park et al. 2002, Swart et al. 2008). These seals preferentially selected the edge of cyclonic eddies, surrounded by an intense eddy flow, in which to forage. However, all the seals travelling within the Polar Frontal Zone could not be clearly associated with eddies, which indicates that eddies are not the only favourable foraging habitat within this region, and in this case, the identification of oceanographic features associated with favorable foraging conditions requires additional work.

The lack of interest of a part of seals for these structures can be also explained by a probable spatialtemporal disconnect between the prey and primary/ secondary productivity associated with eddies, hence a weaker habitat association, which could also be induced by the low accuracy of Argos locations. Moreover, unclear associations between seals and eddies could be related to the data set provided by altimeter readings, for which only temperature variability has been considered in the calculation of sea levels and currents. However, Maes (1998) pointed out that water masses of varying salinities (densities) could affect the use of altimetry to correctly estimate sea levels and currents.

The global eddy field described in our study is a highly dynamic environment. However, elephant seal movements were not affected by the direction of currents during the non-foraging phase or inside the intensive foraging zone. This was surprising, as currents should affect the swimming ability of diving predators, which have to deal with the cost of swimming. Currents influence marine predator such as turtles (Luschi et al. 2003) and breeding king penguins Aptenodytes patagonicus that tend to swim in a similar direction as does the current when travelling from the colony to the foraging area (Cotté et al. 2007). The difference as observed in our results could be explained by the swimming speed of seals. Indeed, while turtles have a swimming speed of the same order of magnitude as speed of the current, elephant seals are substantially faster than the ambient current (by a factor of at least 10). Moreover, seals were at sea for a longer period during their post-moulting trip, and therefore they were not directly affected by the temporal constraints of the breeding season. Then, since seals regularly reach great depths when travelling, currents at these depths may be disconnected to currents estimated from SLA at the surface or subsurface.

Even though there did not appear to be a direct influence of ocean currents on the seals' movements, they 
a)
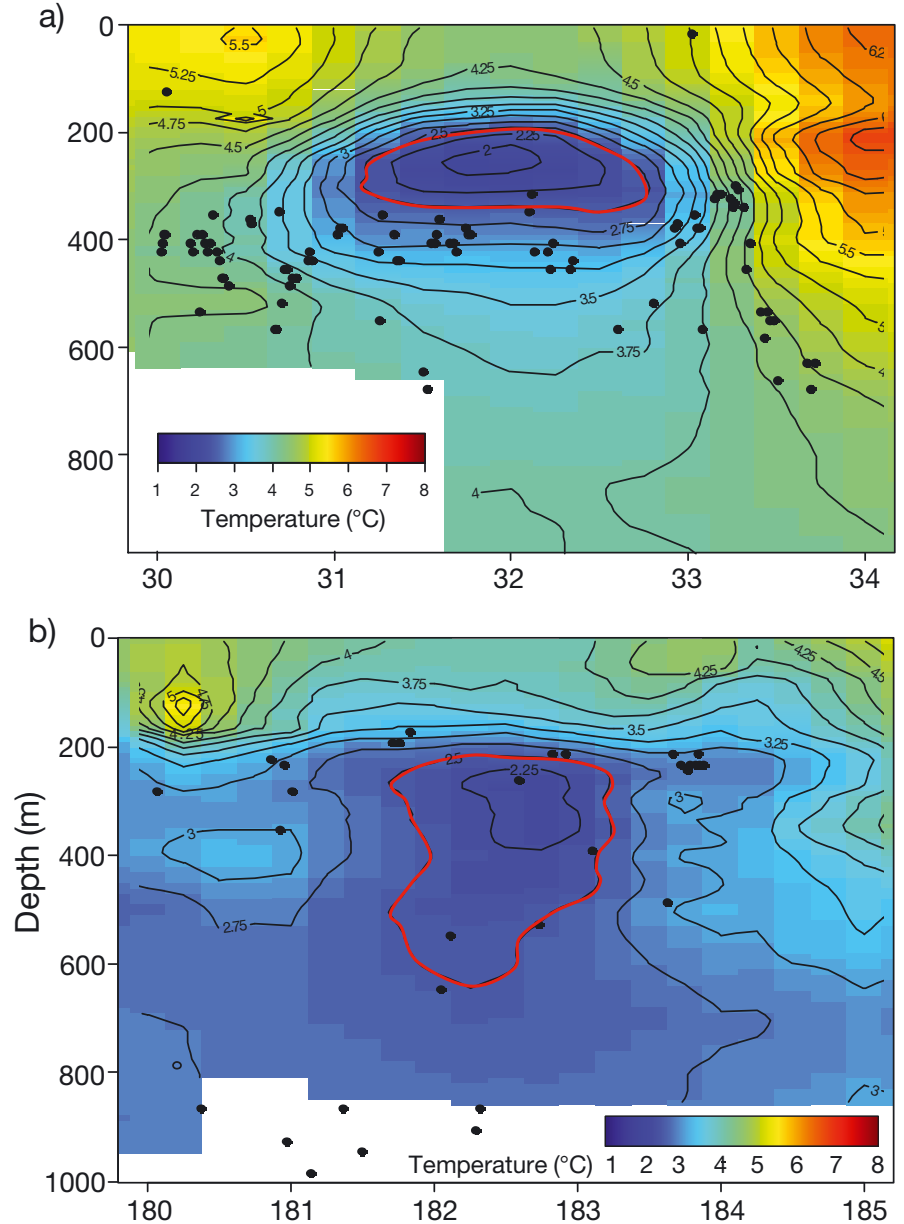

c)

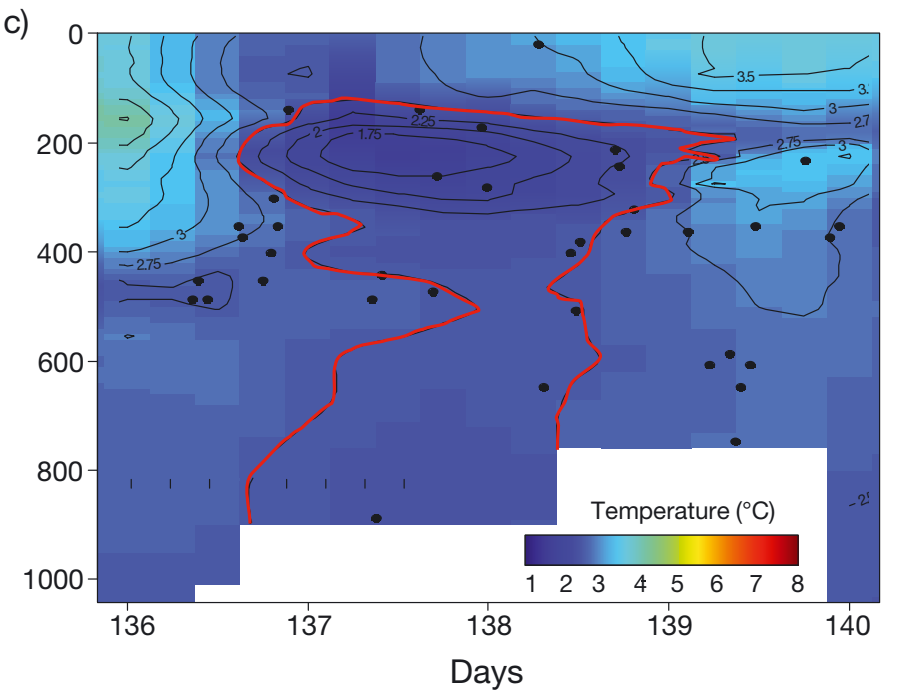

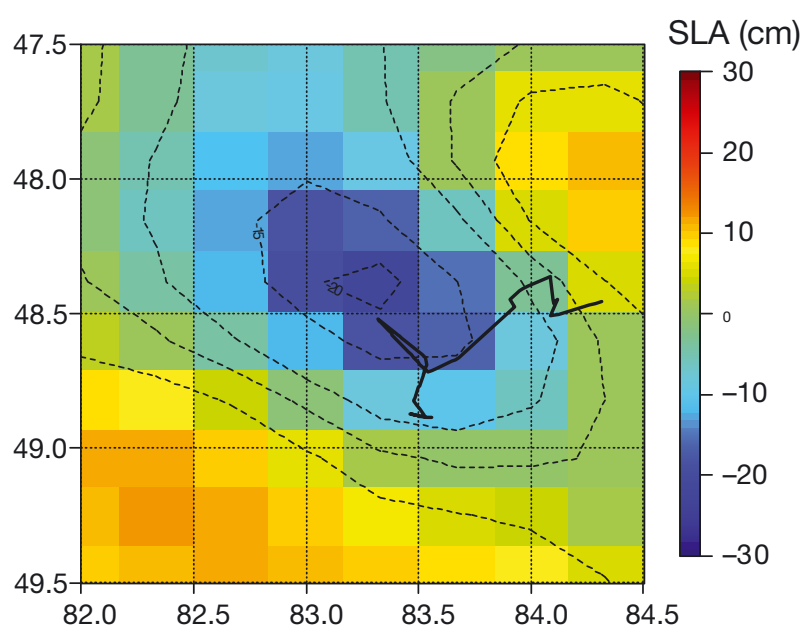
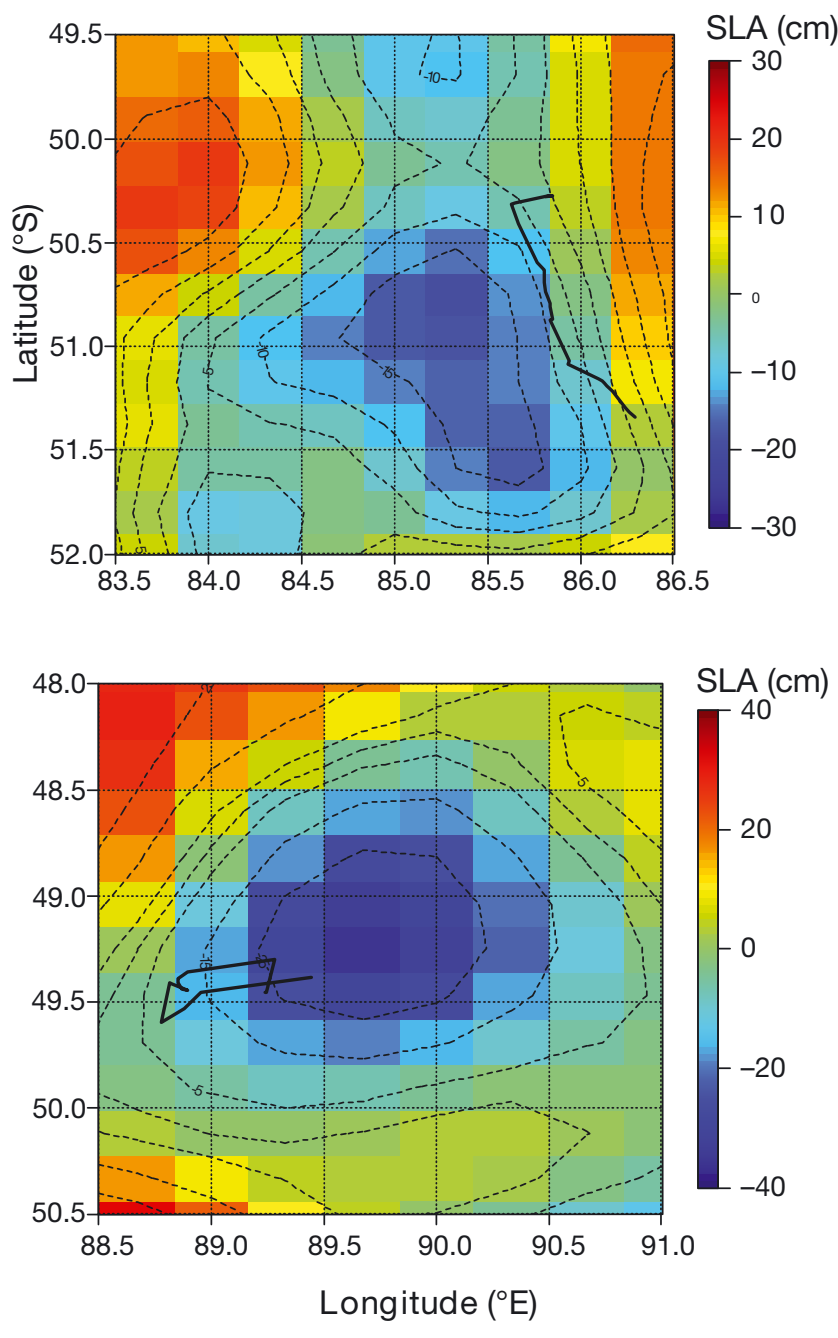

Fig. 7. Mirounga leonina. (a to e) Vertical cross sections in temperature $\left({ }^{\circ} \mathrm{C}\right.$ ) for 5 different eddies targeted by 5 different elephant seals in 2005 and 2007. Left panels: vertical temperature sections of these eddies and the maximum diving depth of seals (black dots). The cold core $\left(<2^{\circ} \mathrm{C}\right)$ appears between 200 and $400 \mathrm{~m}$. The eddies are, in general, defined by the $2.5^{\circ} \mathrm{C}$ isotherm (red line) to at least $900 \mathrm{~m}$. Right panels: negative sea level anomalies (SLAs) corresponding to the eddies and the track of seals (black lines) 

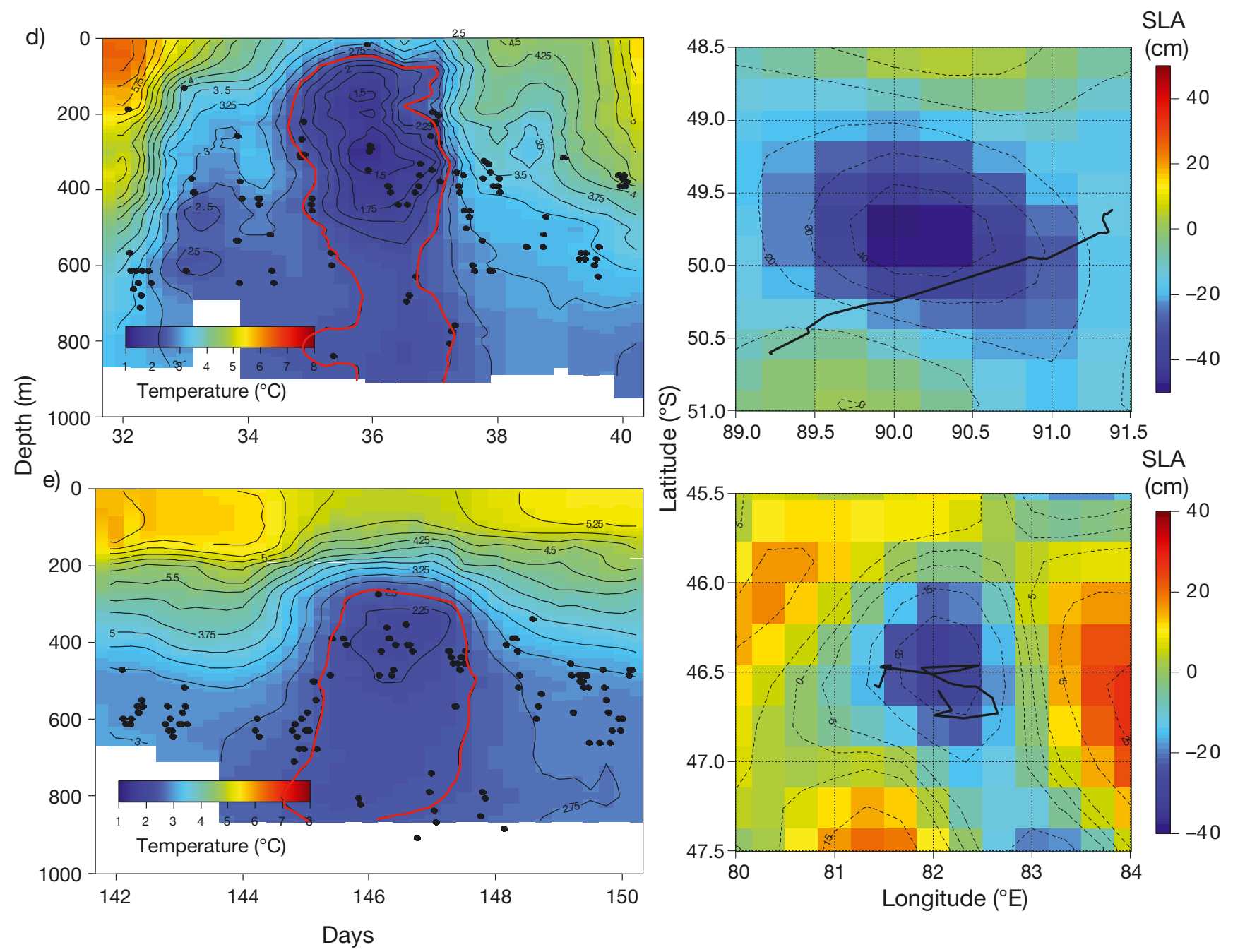

Fig. 7 (continued)

may generate favourable conditions for foraging. (1) At a larger scale, a previous study showed that phytoplankton blooms occur in the vicinity of many topographic structures, particularly around Kerguelen Island and its adjacent plateau (Blain et al. 2007). Based on global water circulation in the ACC region, this bloom stretches to the east and could be partially concentrated in eddies. This could explain why almost all seals traveled east of Kerguelen Island. (2) The seals prefer cyclonic eddies probably because of the physical characteristics of these structures. The cyclonic circulation of cold-core eddies advects horizontally nutrient-rich water toward the surface. In our study, this fact supports the relationship between cyclonic eddies targeted by seals and higher eddy kinetic energy associated with intense mixing activity. Phytoplankton thrives on these pulses of nutrients, and blooms associated with cold-core eddies fuel food webs and attract predators (e.g. Kiørboe 1993). (3) Cyclonic eddies bring water and nutrients up from the depths to the surface.
Thus, in a spin-up situation, upwelling occurs at the centre, and convergence (horizontal concentration of productivity and prey) occurs at the edge. These features influence seal behaviour and, as a result, they dive deeper within the cyclonic structures where they spend more time at the edge. Several foraging predators, including elephant seals, dive in association with thermoclines, which are strong physical discontinuities that concentrate potential prey items (Charrassin \& Bost 2001, Biuw et al. 2007). Even if elephant seals are noted for their important diving capabilities, diving cost probably increases with depth. Thus, whether thermoclines do occur at shallower depths within cyclonic eddies, these structures lead to more accessible concentration of prey at shallow depths (Polovina et al. 2006) and induce a reduction of diving effort. This may explain why seals prefer cyclonic eddies in which to forage. Finally, mesoscale eddies, and particularly the cyclonic eddies, may represent major oceanic structures for diving predators in terms of pro- 
ductivity, aggregation of resources or accessibility of prey. As we lack information on resource distribution, it is difficult to conclude which aspect of these features elephant seals are 'choosing'. However, our results indicate that these 3 components act synergistically within cyclonic structures.

To go further, it would be informative to track eddies from their initial formation to observe spatial and temporal changes in these structures and determine the conditions favorable for elephant seals. Moreover, the eddy field forms a dynamic continuum where each eddy interacts with adjoining eddies, creating submesoscale frontal meanders or filaments. These features give rise to convergences and vertical movements of waters and can concentrate zooplankton and micronekton (Pakhomov \& Fronemann 2000) that are preyed upon by fish, such as myctophids (Pakhomov et al. 1996), and presumably attract predators like elephant seals (Hyrenbach et al. 2006). More information on the influence of these finer-scale structures could increase our knowledge of biophysical interactions in the pelagic environment.

To improve our results and assess the productivity of cyclonic eddies, we need to use ocean colour satellite images to measure primary production. However, the Southern Ocean is often obscured by a persistent cloud layer, precluding satellite detection of phytoplankton blooms (Arrigo et al. 1997). Moreover, satellites scan the sea surface, while deep fluorescence maximums are usually found at depth within the Polar Frontal Zone of the ACC (Quéguiner \& Brzezinsky, 2002). Therefore, the primary production of this region is often underestimated and to determine whether a 3dimensional structure is really productive remains difficult. To complement satellite measurements, physical data directly recorded in depth by elephant seals will be crucial for a better understanding of 3-dimensional structures and their attractiveness to diving predators. A new generation of loggers deployed on seals recording fluorescence at depth together with temperature and salinity will be especially promising for this purpose (Charrassin et al. 2010).

The present study was also carried out during winter when productivity is minimal compared with the summer. Therefore, the relationship between primary production and elephant seals may not be direct. Resources associated with eddies may not be directly related to high concentrations of phytoplankton, due to a spatio-temporal lag between trophic levels. A previous study conducted in the Pacific Ocean showed that Pacific sardine Sardinops sagax larvae were most abundant offshore associated with eddies, while sardine egg density, chlorophyll biomass and zooplankton volume were greatest inshore (Logerwell \& Smith 2001).
In the meantime, the present study provided new insights into the foraging behaviour of diving predators related to mesoscale eddies in high latitudes. It highlights the potential role of cyclonic structures as a major driving force for the biological production and prey aggregation and offers new ideas to explain the distribution of large diving predators such as elephant seals in this part of the Southern Ocean.

Acknowledgements. This work was included in 2 international research programs: Southern Elephant Seals as Oceanographic Samplers (SEaOS) and Marine Mammal Exploration of the Oceans Pole to Pole (MEOP), and also in a national research program (no. 109) supported by Institut Paul Emile Victor (IPEV). The Territoire des Terres Australes et Antarctiques Françaises (TAAF), the Region PoitouCharentes, the Centre National d'Etudes Spatiales (CNESprogramme Tosca) and the group CORIOLIS-MERCATOR contributed considerably to this study. The authors thank the members of the 53th, 54th and 55th research missions at Kerguelen Island and the IPEV logistical staff for their assistance in the field. We particularly thank M. Biuw, I. Field, C. McMahon, M. Hindell, J. B. Charrassin and F. Roquet for their assistance in the seals equipment. The ethics committee of the French Polar Institute (IPEV) approved this study. All seals in this study were cared for in accordance with IPEV guidelines.

\section{LITERATURE CITED}

Arrigo KR, Worthen DL, Lizotte MP, Dixon P, Dieckman G (1997) Primary production in Antarctic sea-ice. Science 276:394-397

Bailleul F, Charrassin JB, Ezraty R, Girard-Ardhuin F, McMahon CR, Field I, Guinet C (2007a) Southern elephant seals from Kerguelen Islands confronted by Antarctic sea ice. Changes in movements and in diving behaviour. DeepSea Res II 54:343-355

Bailleul F, Charrassin JB, Monestiez P, Roquet F, Biuw M, Guinet C (2007b) Successful foraging zones of southern elephant seals from Kerguelen Islands in relation to oceanographic conditions. Phil Trans R Soc Lond B Biol Sci 362:2169-2181

Bailleul F, Pinaud D, Hindell M, Charrassin JB, Guinet C (2008) Assessment of scale-dependent foraging behaviour in southern elephant seals incorporating the vertical dimension: a development of the First Passage Time method. J Anim Ecol 77:948-957

Bailleul F, Authier M, Ducatez S, Roquet F, Charrassin JB, Cherel Y, Guinet C (2010) Looking at the unseen: combining animal bio-logging and stable isotopes to reveal a shift in the ecological niche of a deep diving predator. Ecography (published online) doi: 10.1111/j.1600-0587. 2009.06034.x

Bakun A (2006) Fronts and eddies as key structures in the habitat of marine fish larvae: opportunity, adaptive response, and competitive advantage. Sci Mar 70(Suppl 2): 105-122

Biuw M, McConnell BJ, Bradshaw CJA, Burton HR, Fedak MA (2003) Blubber and buoyancy: monitoring the body condition of free-ranging seals using simple dive characteristics. J Exp Biol 206:3405-3423

> Biuw M, Boehme L, Guinet C, Hindell M and others (2007) Variations in behaviour and condition of a Southern Ocean top predator in relation to in situ oceanographic conditions. Proc Natl Acad Sci USA 104:13705-13710 
Blain S, Quéguiner B, Armand L, Belviso S and others (2007) Effect of natural iron fertilization on carbon sequestration in the Southern Ocean. Nature 446:1070-1074

Campagna C, Le Boeuf BJ, Blackwell SB, Crocker DE, Quintana F (1995) Diving behaviour and foraging location of female southern elephant seals from Patagonia. J Zool 236:55-71

Campagna C, Piola AR, Marin MR, Lewis M, Fernández T (2006) Southern elephant seals trajectories, fronts and eddies in the Brazil/Malvinas confluence. Deep-Sea Res I 53:1907-1924

- Charrassin JB, Bost CA (2001) Utilization of the oceanic habitat by king penguins over the annual cycle. Mar Ecol Prog Ser 221:285-297

Charrassin JB, Hindell M, Roquet F, Biuw M and others (2008) Southern Ocean frontal structure and sea ice formation rates revealed by elephant seals. Proc Natl Acad Sci USA 105:11634-11639

Charrassin JB, Roquet F, Park YH, Bailleul F and others (2010) New insights into Southern Ocean physical and biological processes revealed by instrumented elephant seals. Community White Paper. In: Hall J, Harrison DE, Stammer D (eds) Proceedings of OceanObs'09: Sustained Ocean Observations and Information for Society (Vol 2), 21-25 September 2009, Venice, Italy. ESA Publication WPP-306

Cotté C, Park YH, Guinet C, Bost CA (2007) Movements of foraging king penguins through marine mesoscale eddies. Proc Biol Sci 274:2385-2391

Davis RW, Ortega-Ortiz JG, Ribic CA, Evans WE and others (2002) Cetacean habitat in the northern oceanic Gulf of Mexico. Deep-Sea Res I 49:121-142

Elhmaïdi D, Provenzale A, Babiano A (1993) Elementary topology of two-dimensional turbulence from a Lagrangian viewpoint and single-particle dispersion. J Fluid Mech 257:533-558

Fauchald P, Tveraa T (2003) Using first-passage time in the analysis of area-restricted search and habitat selection. Ecology 84:282-288

Fedak MA (2004) Marine mammals as platforms for oceanographic sampling: a "win/win" situation for biology and operational oceanography. Mem Natl Inst Polar Res 58(Spec Issue):133-147

Ferraroli S, Georges JY, Gaspar P, Le Maho Y (2004) Endangered species: where leatherback turtles meet fisheries. Nature 429:521-522

Field IC, Bradshaw CJA, McMahon CR, Harrington J, Burton HR (2002) Effects of age, size and condition of elephant seals (Mirounga leonina) on their intravenous anaesthesia with tiletamine and zolazepam. Vet Rec 151:235-240

Fu LL, Stammer D, Leben RR, Chelton DB (2003) Improved spatial resolution of ocean surface topography from the T/P-Jason-1 altimeter mission. Eos Trans Am Geophys Union 84(26):241, doi:10.1029/2003EO260002

> Hindell MA, Lea MA (1998) Heart rate, swimming speed, and estimated oxygen consumption of a free-ranging southern elephant seal. Physiol Biochem Zool 71:74-84

Hindell MA, Slip DJ, Burton HR (1991) The diving behaviour of adult male and female southern elephant seals, Mirounga leonina (Pinnipedia: Phocidae). Aust J Zool 39: 595-619

> Hindell MA, Bradshaw CJA, Sumner MD, Michael KJ, Burton HR (2003) Dispersal of female southern elephant seals and their prey consumption during the austral summer: relevance to management and oceanographic zones. J Appl Ecol 40:703-715

Hooker SK, Biuw M, McConnell BJ, Miller PJ, Sparling CE
(2007) Bio-logging science: logging and relaying physical and biological data using animal-attached tags. Deep-Sea Res II 54:177-182

> Hyrenbach KD, Veit RR, Weimerskirch H, Hunt GL Jr (2006) Seabirds associations with mesoscale eddies: the subtropical Indian Ocean. Mar Ecol Prog Ser 324:271-279

Kiørboe T (1993) Turbulence, phytoplankton cell size, and the structure of pelagic food webs. Adv Mar Biol 29:1-72

Kostianoy AG, Ginzburg AI, Frankignoulle M, Dellile B (2004) Fronts in the Southern Indian Ocean as inferred from satellite sea surface temperature data. J Mar Syst 45: $55-73$

Lesage V, Hammill MO, Kovacs KM (1999) Functional classification of harbor seal (Phoca vitulina) dives using depth profiles, swimming velocity, and an index of foraging success. Can J Zool 77:74-87

Lévy M (2008) The modulation of biological production by oceanic mesoscale turbulence. Lect Notes Phys 744: 219-261

Logerwell EA, Smith PE (2001) Mesoscale eddies and survival of late stage Pacific sardine (Sardinops sagax) larvae. Fish Oceanogr 10:13-25

Luschi P, Hays GC, Papi F (2003) A review of long-distance movements by marine turtles, and the possible role of ocean currents. Oikos 103:293-302

Maes C (1998) Estimating the influence of salinity on sea level anomaly in the ocean. Geophys Res Lett 25:3551-3554

McConnell BJ, Chambers C, Fedak MA (1992) Foraging ecology of southern elephant seals in relation to the bathymetry and productivity of the Southern Ocean. Antarct Sci 4 : 393-398

> McMahon CR, Burton HR, McLean S, Slip D, Bester M (2000) Field immobilisation of southern elephant seals with intravenous tiletamine and zolazepam. Vet Rec 146:251-254

Nel DC, Lutjeharms JRE, Pakhomov EA, Ansorge IJ, Ryan PG, Klages NTW (2001) Exploitation of mesoscale oceanographic features by grey-headed albatross Thalassarche chrysostoma in the Southern Indian Ocean. Mar Ecol Prog Ser 217:15-26

Okubo A (1970) Horizontal dispersion of floatable particles in the vicinity of velocity singularities such as convergences. Deep-Sea Res 17:445-454

>lson D (1991) Rings in the ocean. Annu Rev Earth Planet Sci 19:283-311

> Pakhomov EA, Fronemann PW (2000) Composition and spatial variability of macrozooplankton and micronekton within the Antarctic Polar Frontal Zone of the Indian Ocean during austral summer 1997. Polar Biol 23:410-419

Pakhomov EA, Perissinotto R, McQuaid CD (1996) Prey composition and daily rations of myctophid fishes in the Southern Ocean. Mar Ecol Prog Ser 134:1-14

> Park YH, Pollard RT, Read JF, Leboucher V (2002) A quasisynoptic view of the frontal circulation in the Crozet Basin during the Antares-4 cruise. Deep-Sea Res II 49: 1823-1842

Pinaud D, Weimerskirch H (2005) Scale-dependent habitat use in a long-ranging central place predator. J Anim Ecol 74:852-863

Polovina JJ, Uchida I, Balazs GH, Howell EA, Parker DM, Dutton MP (2006) The Kuroshio extension bifurcation region: a pelagic hotspot for juvenile loggerhead sea turtles. Deep-Sea Res II 53:326-339

Quéguiner B, Brzezinsky M (2002) Biogenic silica production rates and particulate organic matter distribution in the Atlantic sector of the Southern Ocean, during austral spring 1992. Deep-Sea Res II 49:1765-1786

Ream RR, Sterling JT, Loughlin TR (2005) Oceanographic fea- 
tures related to northern fur seal migratory movements. Deep-Sea Res II 52:823-843

Schreer JF, Kovacs KM, O'Hara Hines RJ (2001) Comparative diving patterns of pinnipeds and seabirds. Ecol Monogr 71:137-162

Strass VH, Naveira Garabato AC, Pollard RT, Fischer HI and others (2002) Mesoscale frontal dynamics: shaping the environment of primary production in the Antarctic Circumpolar Current. Deep-Sea Res II 49:3735-3769

Editorial responsibility: Michael Castellini,

Fairbanks, Alaska, USA
Swart NC, Ansorge IJ, Lutjeharms JRE (2008) Detailed characterization of a cold Antarctic eddy. J Geophys Res 113: C01009, doi:10.1029/2007JC004190

Weimerskirch H, Le Corre M, Jacquemet S, Potier M, Marsac DP (2004) Foraging strategy of a top predator in tropical waters: great frigatebirds in the Mozambique Channel. Mar Ecol Prog Ser 275:297-308

Weiss J (1991) The dynamics of enstrophy transfer in twodimensional hydrodynamics. Physica D 48:273-294

Submitted: September 3, 2009; Accepted: February 26, 2010 Proofs received from author(s): May 14, 2010 